\title{
Measles outbreaks are still here to stay
}

Hong Kong Med J 2020;26:551

https://doi.org/10.12809/hkmj198319

To the Editor-Measles outbreaks have been reported in the Hong Kong Medical Journal in the past 2 years. ${ }^{1,2}$ Such outbreaks occur worldwide, including in countries where measles was previously considered eliminated. In March 2019, there was a measles outbreak at Hong Kong International Airport involving airport workers, some with documented evidence of at least two doses of measles vaccinations. ${ }^{3}$ Fortunately, the patients were all relatively young adults who experienced with mild symptoms, and the basic reproduction number of these cases was not high. In response to this outbreak, control measures at the airport included a vaccination programme and measles antibody testing for airport staff. The Hong Kong childhood immunisation schedule was also revised, so that the second dose of the MMRV (measles, mumps, rubella and varicella) vaccination is given at age 18 months (previously given at age 6 years) to enhance protection against measles.

Measles vaccination uptake rate is declining due to pockets of unvaccinated communities and anti-vaccination movements, both of which might have contributed to the recent outbreaks. To eliminate measles, a continuously high (>95\%) level of vaccination coverage is required in all areas. Most recent outbreaks of measles in developed countries have been imported cases; thus, they are closely linked to the aviation industry. Early recognition of disease outbreak could prevent a global pandemic. Therefore, it is crucial to have contingency plans at every airport to prevent the spreading of contagious diseases. Travellers should ensure their vaccination status is up-to-date with two doses of measles vaccination; infants from 6 months of age should receive a supplementary dose of measles vaccine if they are travelling to areas with measles outbreaks. ${ }^{4}$ Affected patients, especially school-age children, should be isolated and quarantined at home for at least 4 days from the appearance of rash.

The 2019 measles outbreak saw a substantial increase in the number of measles cases reported worldwide relative to 2018. Such outbreaks will occur again if we do not learn from the past. The only hope to truly defeat measles is for humankind to work together.

\section{Author contributions}

The authors had full access to the data, contributed to the study, approved the final version for publication, and takes responsibility for its accuracy and integrity.

\section{Conflicts of interest}

As an Editor of the Journal, KL Hon was excluded from the review process for this letter. The other author has disclosed no conflicts of interest

Karen KY Leung, MB, BS, MRCPCH

KL Hon *, MB, BS, MD

Department of Paediatrics and Adolescent Medicine, The Hong Kong Children's Hospital, Kowloon Bay, Hong Kong

*Corresponding author: ehon@hotmail.com

\section{References}

1. Hon KL, Leung AK, Leung K, Chan GC. Measles outbreak at an international airport: a Hong Kong perspective. Hong Kong Med J 2019;25:331-3.

2. Leung AK, Hon KL, Leong KF, Sergi CM. Measles: a disease often forgotten but not gone. Hong Kong Med J 2018;24:512-20.

3. Centre for Health Protection, Hong Kong SAR Government. Daily update on measles situation in Hong Kong. Available from: https://www.chp.gov.hk/files/pdf/daily_update_on_ measles_cases_in_2019_eng.pdf. Accessed 6 Dec 2019.

4. World Health Organization. WHO advice for international travel in relation to measles. 2019. Available from: https://www.who.int/ith/WHO-advice-for-internationaltravel-in-relation-to-measles.pdf?ua $=1$. Accessed 6 Dec 2019.

\section{Taking a multidisciplinary team approach to better healthcare outcomes for society}

\author{
Hong Kong Med J 2020;26:551-2 \\ https://doi.org/10.12809/hkmj209133
}

To the Editor-Globally, healthcare has become more diverse and complex. A broad range of increasing and emerging challenges are facing people and communities in an unprecedented manner, including population ageing, health inequality, social sustainability, long-term conditions, and coronavirus disease 2019. This calls for an integrated provision of prevention, treatment, and care that extends 
beyond the conventional boundaries of individual disciplines to deal with the wider determinants of health and wellbeing. The importance of a teambased approach in healthcare decision-making and problem-solving has been widely recognised in many countries worldwide. The family doctor teams in China and the multidisciplinary teams in Scotland, United Kingdom, for example, are currently being implemented to conceptualise care regimens as well as coordinate the delivery of complex care across different levels of the healthcare system. In Hong Kong, the multidisciplinary team approach built upon medico-social collaboration has also demonstrated positive impacts in supporting endof-life patients in residential care homes, ${ }^{1}$ reducing the clinical and economic burden of geriatric hip fracture,,$^{2}$ and improving medication safety for chronic disease management. ${ }^{3}$ It is essential to have community participation in these services as this may lead to coproduction of health, giving the most optimal health promotion services. ${ }^{4,5}$

The 'Healthcare for Society', which started as 'Doctor for Society' in August 2012, is a popular section in the Hong Kong Medical Journal. ${ }^{6-8}$ Medical students serve as interviewers to report various activities and outstanding achievements of medical doctors and medicine-related professionals who have made substantial voluntary contributions to Hong Kong society. These community services are unconditional and most are dedicated to vulnerable groups. ${ }^{9-11}$

In view of the change in healthcare delivery and the need to prepare healthcare professionals for tackling the ever-increasing complexity of challenges, it is time to consider expanding the scope of this inspirational showcase from individual exemplars to all members in the team as a whole from a multidisciplinary perspective. The stories of these exemplary teams would convey farreaching messages to encourage our colleagues and students who are the next generation of healthcare professionals to dedicate themselves to healthcare community. The collections of informative showcases shall substantially contribute to novel models of care delivery to improve population wellbeing beyond the realms of clinical encounters and medical practices. Meanwhile, community services play a role in medical education. ${ }^{12}$ Student interviewers could greatly benefit from learning how professionals from varying disciplines work cohesively, communicate efficiently, and share resources cooperatively across sectors and disciplines under strengthened leadership to improve population health outcomes and achieve excellence in healthcare for the community at large.

\section{Author contributions}

The author had full access to the data, contributed to the study, approved the final version for publication, and takes responsibility for its accuracy and integrity.

\section{Conflicts of interest}

As an Editor of the Journal, HHX Wang was not involved in the review of this letter. The author has disclosed no other conflicts of interest.

\section{Harry HX Wang ${ }^{1,2,3}$, PhD}

1 School of Public Health, Sun Yat-Sen University, China

2 The Jockey Club School of Public Health and Primary Care, Faculty of Medicine, The Chinese University of Hong Kong, Hong Kong

${ }_{3}^{3}$ General Practice and Primary Care, Institute of Health and Wellbeing, University of Glasgow, Scotland, United Kingdom

*Corresponding author: haoxiangwang@163.com; Haoxiang.Wang@glasgow.ac.uk

\section{References}

1. Luk JK. End-of-life services for older people in residential care homes in Hong Kong. Hong Kong Med J 2018;24:63-7.

2. Chung AY, Anand S, Wong IC, et al. Improving medication safety and diabetes management in Hong Kong: a multidisciplinary approach. Hong Kong Med J 2017;23:158-67.

3. Leung FK, Lau TW, Yuen GW, Chan EM, Chan P, Lam RY. Effectiveness of a multidisciplinary approach to geriatric hip fractures in improving clinical outcomes and cost of care. Hong Kong Med J 2018;24 Suppl 2:45-7.

4. Marston C, Renedo A, Miles S. Community participation is crucial in a pandemic. Lancet 2020;395:1676-8.

5. Marston C, Hinton R, Kean S, et al. Community participation for transformative action on women's, children's and adolescents' health. Bull World Health Organ 2016;94:376-82.

6. Wong M, Chan KS, Chu LW, Wong TW. Doctor for Society: a corner to showcase exemplary models and promote volunteerism. Hong Kong Med J 2012;18:268-9.

7. Lai EC, Wong MC. Doctor for Society: paying tribute to role models of humanitarianism and professionalism. Hong Kong Med J 2017;23:432.

8. Wong MC, Lai EC. "Healthcare for Society"-a column featuring outstanding community contributions. Hong Kong Med J 2019;25:4-5.

9. Yau R, Lau N. World volunteer and carer for bones and minds: an interview with Dr Chi-wai Chan. Hong Kong Med J 2019;25:501-2.

10. Lam C, Cheuk N, Yeung C. Healing hearts in paediatrics: an interview with Dr Adolphus Chau. Hong Kong Med J 2019;25:416-8.

11. Tsui M, Chan B. Part of a larger whole: serving in the Government Flying Service. An interview with Dr Ralph Cheung. Hong Kong Med J 2018;24:644-5.

12. Muller D, Meah Y, Griffith J, et al. The role of social and community service in medical education: the next 100 years. Acad Med 2010;85:302-9. 